\title{
Leadership development: an essential ingredient in supporting nursing unit managers
}

This article was published in the following Dove Press journal:

Journal of Healthcare Leadership

10 December 2013

Number of times this article has been viewed

\section{Valerie Wilson ${ }^{1,2}$ \\ Sheree Paterson ${ }^{3}$ \\ Kelly Kornman'}

'Nursing Research and Practice Development Unit, The Children's Hospital at Westmead, Westmead, NSW, Australia; ${ }^{2}$ Faculty of Nursing Midwifery Health, The University of Technology, Sydney, Broadway, NSW, Australia; ${ }^{3}$ Formerly of the Nursing Research and Practice Development Unit, The Children's Hospital at Westmead, Westmead, NSW, Australia
Correspondence: Valerie Wilson The Children's Hospital at Westmead, Cnr Hawkesbury Road and Hainsworth Street, Westmead, NSW, Australia, 2I 45 Tel +6I 298453093

Fax +6I 298453082

Email valerie.wilson@health.nsw.gov.au
Purpose: The aim of the leadership development program was to enhance participants' understanding of person-centered leadership in the context of their nursing unit manager (NUM) roles.

Materials and methods: This article details the results of the NUM leadership development program (LDP). Twenty-one NUMs from an Australian pediatric hospital participated in the 8-month program. The evaluation encompassed a group claims/concerns/issues session, one-onone interviews, and written feedback. Data were themed using a four-step sequential process. Results: The NUM LDP had a positive impact on the leadership practices of the participants. Six key themes were identified from the evaluation: "forming the group"; "being in the group"; "translating into practice"; "how we see ourselves; how do we want to be seen?"; "positive outcomes for me"; and "positive outcomes for others".

Conclusion: This study showed improvements in the leadership understanding and practice of NUMs who participated in the program. Further research, particularly into the transferability of skills and active participatory aspects of these types of evaluation studies, is required.

Keywords: nurse, evaluation, person-centered care, experiential learning

\section{Introduction}

Effective nursing leadership is strongly linked to the provision of safe, high-quality person-centered care. ${ }^{1}$ In particular, transformational leadership is associated with enhanced patient care. ${ }^{2}$ Effective nurse leaders are described as possessing knowledge and skills in emotional intelligence, particularly insight and empathy, good communication, and giving and receiving feedback. ${ }^{3,4}$ Other beneficial leadership attributes include the ability to act as an inspirational role model and to employ clarity. ${ }^{6,7}$

The literature highlights the components of effective person-centered leadership as an approach to leading, where there is an ability to choose the right style in the right situation, and is described as achieving balance between transactional and transformational leadership styles. ${ }^{7,8}$ McGuire and Kennerly ${ }^{7}$ describe transformational leaders as using ideals, inspiration, intellectual stimulation, and individual consideration to influence the behaviors and attitudes of others. Transactional leadership is when the focus is on the contingent reward of followers, where the transactional leader sets goals, gives directions, and uses rewards to reinforce employee behaviors associated with meeting or exceeding established goals. ${ }^{7}$

It has been hypothesized that the health care organizational culture rewards, and thus fosters, transactional styles of leadership. ${ }^{7}$ Edmonstone and Western ${ }^{9}$ caution against adopting a dualistic approach to leadership (transactional and transformational) 
as it does not take into account the complexities of leading people. Person-centered leadership, however, embraces both individual and situational factors. Person-centeredness is defined as respecting and valuing each individual as a unique being with rights, and engaging with them in a way that promotes their dignity, sense of worth, and independence. ${ }^{10}$ Person-centered leadership is emerging as a fundamental component in health care, and there are a range of activities and resources related to this. ${ }^{11}$

Leadership development in organizations has been associated with increased job satisfaction, improved team effectiveness and workplace culture, together with better patient outcomes and health service delivery. ${ }^{12,13}$ Leadership can be learned and is a continual journey where reflection and evaluation are integral. ${ }^{8,14}$ Nursing unit managers (NUMs) manage patient flow and staff issues in their designated departments, wards, or units. This role has been identified as integral to safe care and seamless service delivery. ${ }^{7}$ Investing in the professional development of NUMs is one way of supporting leadership development, particularly person-centered leadership. Internationally, there is a growing body of literature discussing leadership development in health care organizations, ${ }^{14}$ however, there is a paucity of literature related specifically to NUM leadership development programs (LDPs). Therefore, there is little information to inform the ongoing development of nursing managers to support their role as the lynchpin in our health care units. ${ }^{7,15}$ In order to develop a person-centered culture, we suggest that the focus needs to be person-centered leadership. A recent study indicated that nurse managers required leadership support within the health care organization; the nurse managers communicated the challenges they faced regarding the changing health care system, including their desire to provide person-centered care to patients. ${ }^{16}$

The aim of the NUM LDP was to enhance participants' understanding of person-centered leadership in the context of their NUM role.

\section{The leadership development program}

A NUM professional development program was conducted in a large Australian tertiary pediatric public hospital in 2010. The focus of this program was to work with staff members to help them attain a clearer understanding of their roles and to develop effective work cultures. The program offered opportunities for NUMs to consolidate and extend the knowledge and skills they obtained through attending the workshops offered by the state health department, which had the explicit purpose of developing NUMs across the state.
As part of the 2010 program evaluation, interviews were conducted with the participants. The interview questions asked participants to highlight what they would like to see in a future program based on their experiences in 2010. Figure 1 depicts the key concepts guiding future learning objectives: 1) critical reflection and insight; 2) learning for self; 3) developing strategies; and 4) enabling others. Information was also obtained relating to group size, membership, time for meetings, mode of delivery, and preparation for learning. In summary, the recommendations based on the interview themes were that the next iteration of the NUM program should focus on leadership development. This was endorsed by the hospital's nursing executive team.

The framework was used as a basis for co-creating the curriculum and to negotiate the mode of delivery with NUMs. That is, the content, structure, and processes of the $2011 / 2012$ NUM LDP were informed by participant interviews. The program was conducted using a highchallenge/high-support framework that valued participation, experience sharing, experiential and active learning, critical reflection and feedback, and the translation of knowledge and skills into practice. ${ }^{17}$ The program outline is available on request by emailing the investigators.

\section{Materials and methods Setting and study sample}

Twenty-one NUMs across all clinical areas within the hospital participated in the program. Of these, 90\% were female and $10 \%$ male. The NUMs were self-nominated into four discrete groups of four to six participants who met with a facilitator every 4 weeks for 1.5 hours. Each group had NUMs with a range of experience, including those who were new to the role, to NUMs with over 20 years' experience. The program ran from May 2011 to March 2012, with sessions conducted on different days and weeks to meet the needs of each group. The only guideline for self-nomination was that a variety of specialty clinical areas in each group was preferable, to facilitate networking and disperse knowledge.

During the program, group membership changed slightly due to individuals who were temporarily acting NUMs, as well as participants taking long service leave. Groups were consulted prior to new members joining. Experienced facilitators were allocated to each group. Facilitators had knowledge of and experience in both transformational facilitation and leadership. The focus of transformational facilitation is on developing and empowering individuals and teams. The facilitator's role is concerned with enabling the development of reflective learning by helping the NUMs to identify their 


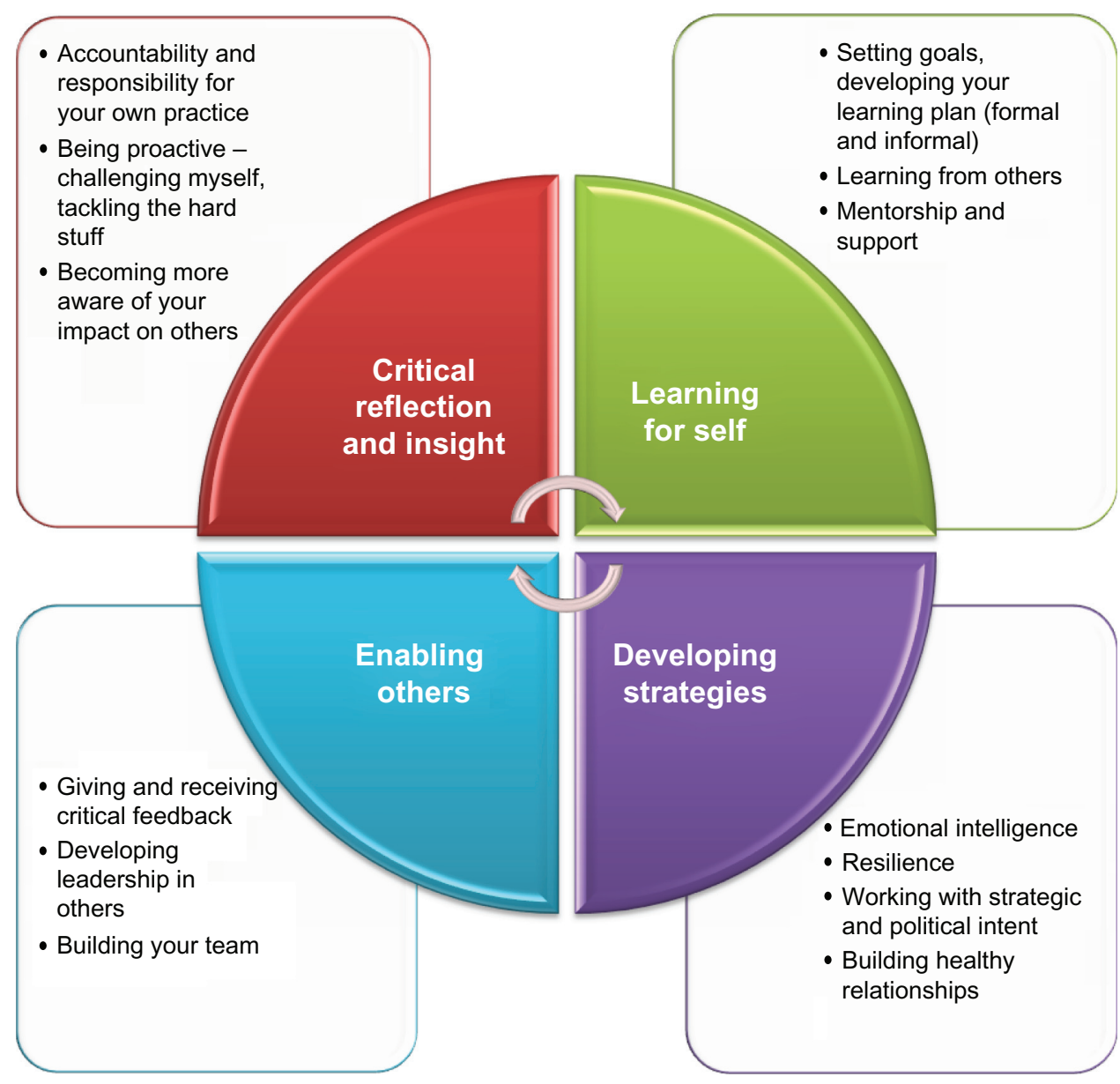

Figure I Nursing unit manager leadership development model.

learning needs, by guiding group processes, by encouraging critical thinking, and by assessing the achievement of learning goals. ${ }^{18}$

The evolving program was influenced by the needs of the program participants, with program details negotiated by the group members. As feedback was received, the NUMs shared their learning needs with each other, and thus were active participants in adjusting content and processes accordingly, co-creating a continually evolving learning space. While this was individualized to each group, common areas for development emerged.

The two facilitators met on a monthly basis to discuss their experiences and to engage in critical reflection, which enabled the sharing of insights and the development of plans for future group meetings.

\section{Evaluation design}

A PRAXIS evaluation framework ${ }^{17}$ was used. Grounded in practice development, the premise underpinning the PRAXIS framework is that evaluation is a continual and dynamic process. Participatory action-oriented approaches were used to collect data throughout the program.

\section{Ethical considerations}

Program participation was mandatory for all NUMs at the request of the hospital nursing executive; however, participation in the research component of the program was voluntary. Appropriate informed consent procedures were developed. Program participants were asked to verbally consent to the use of feedback obtained in the group sessions and the group claims/concerns/issues (CCI) session. Participants were also invited to take part in an interview. Facilitators provided an information sheet to participants regarding the evaluation, and written consent was obtained for the interview. Consent forms were returned to an independent researcher, who could provide further information or answer any of the participants' questions. Ethics approval for the implementation and evaluation of the program was obtained from the local Human Research Ethics Committee. 


\section{Data collection}

Participant data was collected throughout the course of the program (to inform ongoing delivery) and at its conclusion. Participants were provided with an opportunity to contribute to the end of program evaluation via three methods: 1) through a group CCI session, also known as a stakeholders analysis; ${ }^{18}$ 2) a one-on-one interview; or 3) through written feedback. All group members were encouraged to give feedback irrespective of attendance rate or the perceptions they had about their individual learning. The importance of representing a complete picture of the participants' experiences was emphasized to the participants. The three methods that were employed are described as follows:

1. A CCI exercise was undertaken at each of the final four group meetings; this was facilitated using inclusive processes, which aimed to provide group members with equal opportunities to contribute and share their perspectives. The stakeholder analysis enabled group discussions about the program content, and as a consequence, generated further insights to inform the findings. Participants were asked what claims (positive statements) they would like to make about the NUM LDP at both a personal level and as part of their particular group. They were also asked what concerns (negative statements) they had regarding both levels. When discussing the issues, the participants were asked to build on their claims and address their concerns, formatting their issues into questions. The exercise raised critical questions for consideration, which can then be used to inform the planning of future programs.

2. Semi-structured interviews were conducted by an independent researcher who had no involvement in the development or delivery of the NUM LDP, and the interviews lasted approximately 20 minutes. The interviews were audio taped and subsequently de-identified and transcribed. The participants were asked open-ended questions; for example: "What was your experience of the NUM LDP?"; "What have you noticed about your leadership skills over time as a result of being a part of this group?"; "What recommendations would you make for future programs to enhance the experience?" Further unstructured reflective questions evolved from these and were used to facilitate elaboration based on individual interviewee responses. Additionally, participants were asked to share reflective notes recorded throughout the program.

3. Participants were also asked to provide any relevant written feedback regarding the program.

Data collected throughout the program included the learning goals identified by the participants at the start of the program, group attendance, and key information captured in the group meetings, which informed the evaluation. The focus of this paper, however, is on the evaluation that was conducted at the end of the program. Figure 2 represents how process data informed the ongoing program delivery, which ultimately informed the program's evaluation.

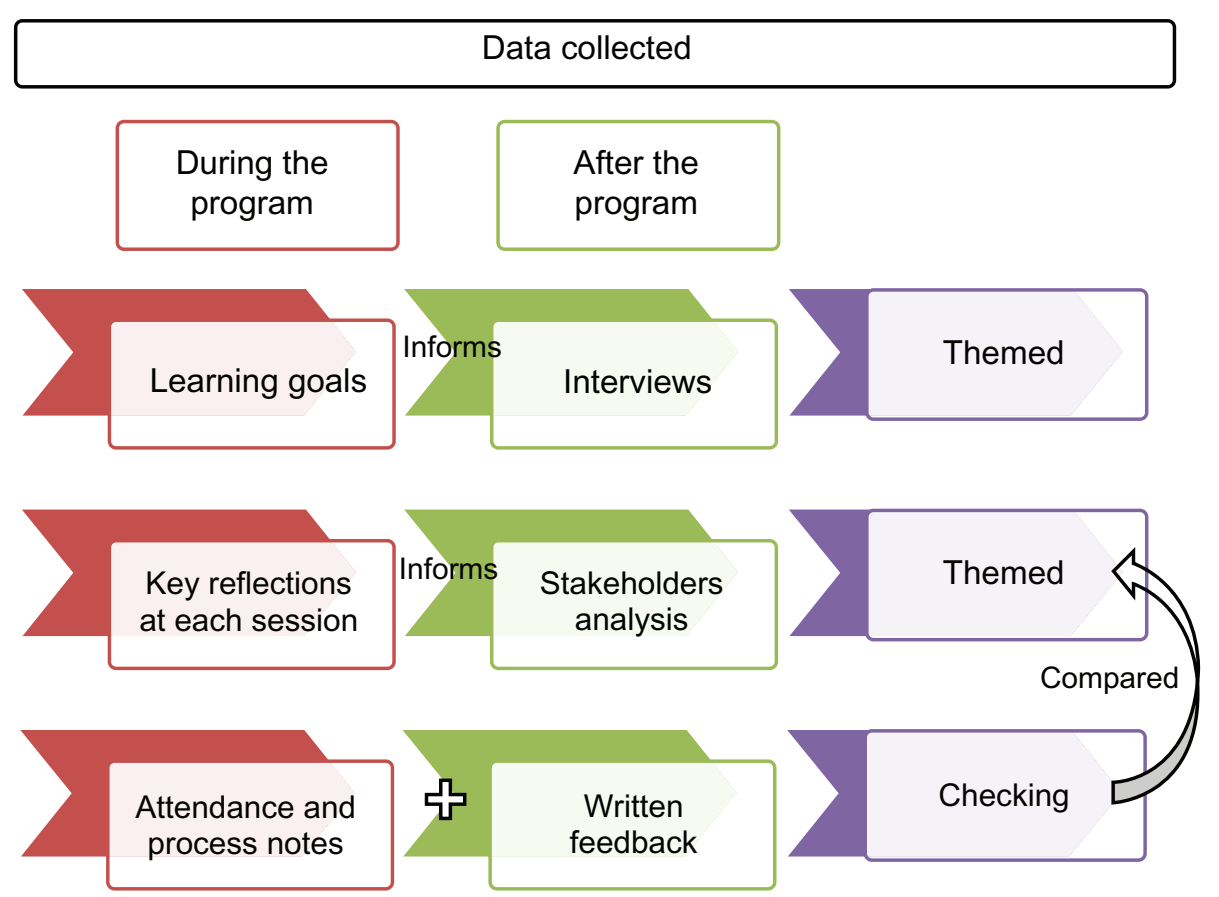

Figure 2 Data collection.

Note: The learning goals help inform the interviews and the key reflections help inform the stakeholder analysis. 


\section{Data analysis}

Thematic analysis was informed by grounded theory. The interview data was themed through a four-step sequential process. Initially, the two facilitators read the transcripts and noted key concepts. A facilitated discussion was conducted where thematic analysis of the data occurred. A third facilitator acted independently to offer critical questions and to optimize objective theming. The one short written feedback form that was submitted by a participant was used as a processchecking mechanism. The collated CCI was then themed and compared. Finally, any additions and revisions that were identified were incorporated. Quotes correlating to the themes were extrapolated to support the findings.

\section{Results}

At the program's conclusion, the groups had a total of 17 NUMs who were still actively participating in the program, with an average of three NUMs attending each session. Participant response rates varied based on the evaluation method used: 16 NUMs participated in the CCI exercise (94\%); seven individual interviews were conducted (41\%); and one short written feedback document was submitted $(6 \%)$. All of the participants who took part in an interview also took part in the CCI.

Six key themes were identified from the evaluation:

1. Forming the group

2. Being in the group

3. Translating into practice
4. How we see ourselves? How do we want to be seen?

5. Positive outcomes for me

6. Positive outcomes for others.

The themes have been clustered around three main areas to illustrate the relationship between the themes identified in the data analysis (Figures 3-5). The results are presented as an overview of each theme with supporting quotes from the CCI session (CCI) or from the participant interviews $(\mathrm{N})$. Due to the nature of the CCI data, they were treated as one dataset to ensure that the data were not readily identified as belonging to a specific group.

\section{Forming the group}

Attendance at each group was variable. Reasons given for sporadic attendance were timing (despite nominating meeting times), as well as other priorities and demands of the department; this was especially problematic for the NUMs who provided direct clinical care. The transient nature of group membership, particularly where acting NUMs went back to their substantive position, also influenced attendance. Group membership was also impacted by staff members who went on maternity leave, and new NUMs who came onboard.

As highlighted in Figure 3, several issues relating to group formation have been identified. Some NUMs reported that they valued the consistency and size of the group membership: "group membership ... good to be part of a small group - get to know others that I don't always

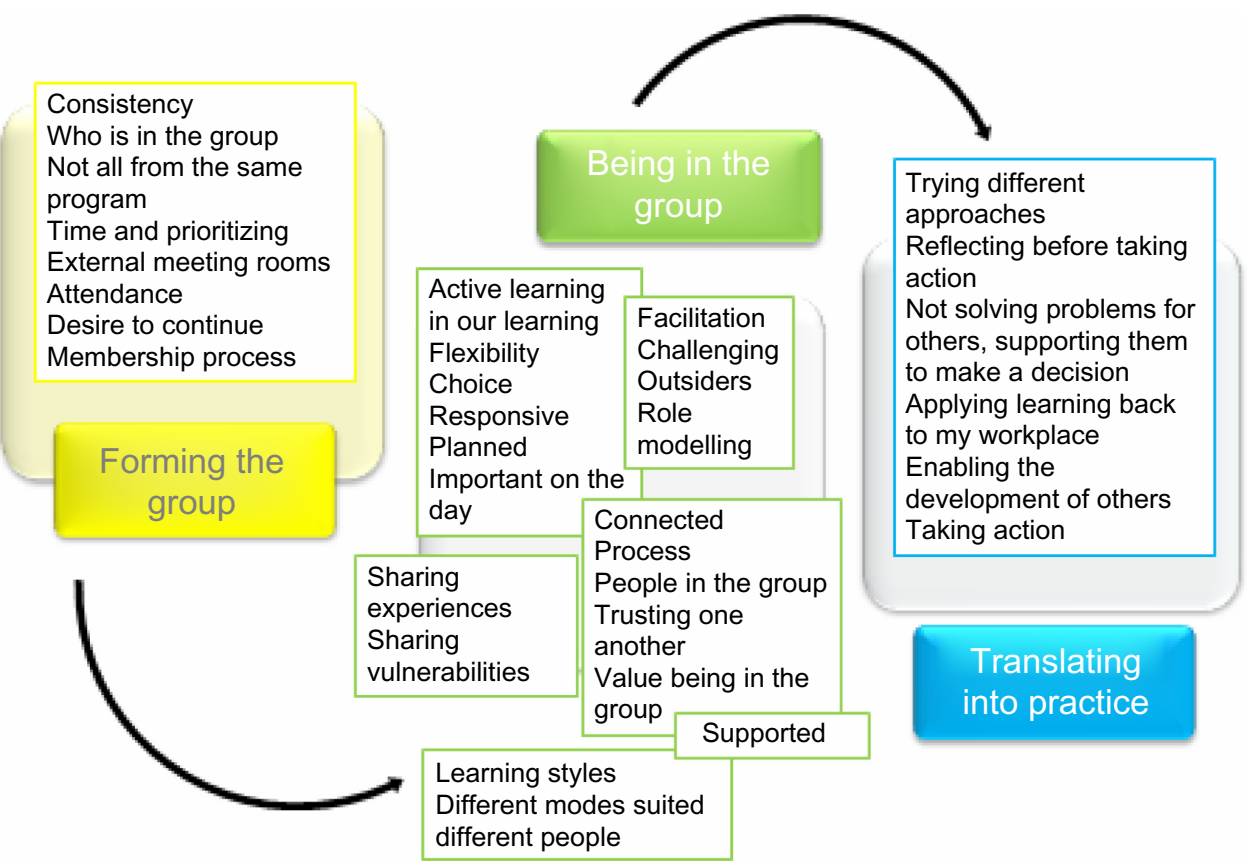

Figure 3 The group and group process (themes and subthemes). 
How do we see

ourselves and how do we want to be seen?

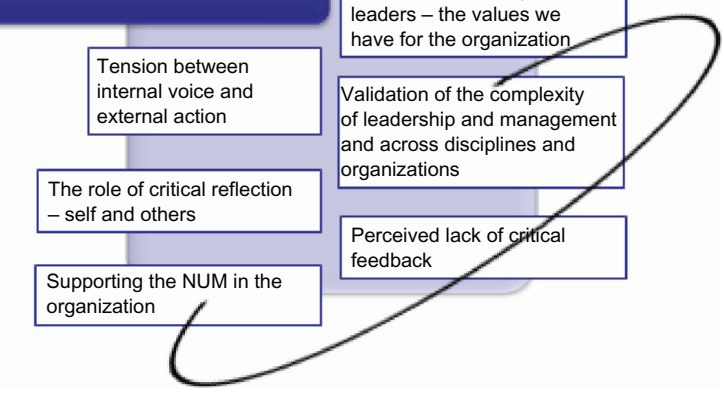

Figure 4 NUM perceptions.

Abbreviation: NUM, nursing unit manager.

work with" [CCI], while on the other hand, some expressed frustration at the fluctuating attendance and the impact this had: "what was not so good was the inconsistency and poor attendance" [N2]. The challenges of navigating competing priorities in the workplace were acknowledged: "I think it's something that is good for your soul. I think as a NUM ... those are the things you often shelve ... I don't know what you do about that" [N3]. The ability to work with NUMs they would not normally engage with was identified as a positive impact of this program: "I think generally it was nice to have a diverse group with very different departments but living in the same world really" [N6]. Creating a "space to learn" was also highlighted as an important factor: "it was good to get away from frontline care in a quiet environment" [CCI].

\section{Being in the group}

Numerous factors relating to the group experience were identified (Figure 3). The NUMs felt they were active participants in guiding their own learning, enjoying both

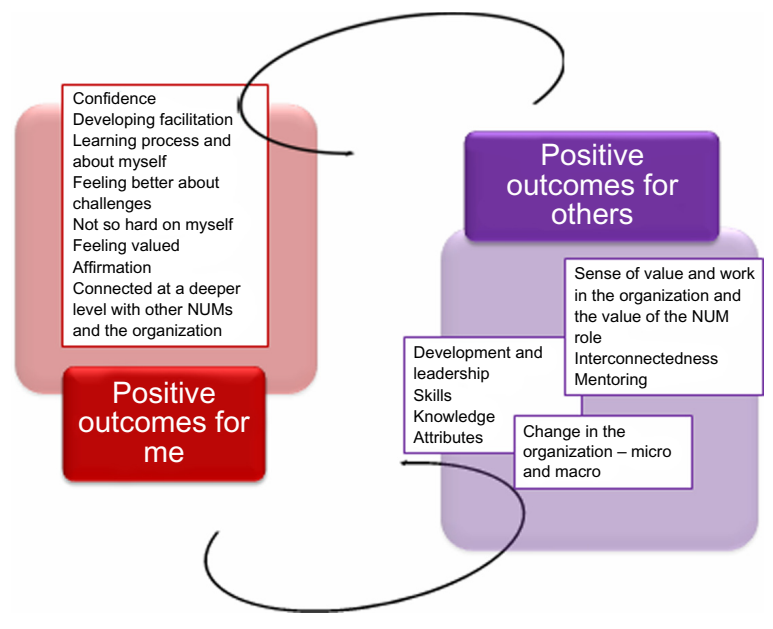

Figure 5 Positive individual and group outcomes. Abbreviation: NUM, nursing unit manager. flexibility and choice: "if someone had a particular issue and there was a drama of the day or the week ... that's what we needed to focus on in that session so that's what we did" [N5]. The program was referred to as being responsive to the respondents' learning needs on the day that the session was conducted; however, it was recognized that forward planning supported a purpose and structure for development to occur. "[We] always had a backup plan and we could choose what we wanted to do and she would give us ... options" [N5]. It was recognized that participants' learning styles were varied, and that different modes suited different people.

The external facilitator was identified as a role model who provided challenges:

[The] facilitator is very open and challenges us ... I think

[that's] exactly what we need. I don't think the group would function if there wasn't the challenge in what we needed to do. I think it definitely needs to be facilitated by an outsider. [N6]

A strong bond of trust was described as being central to the groups' comfort when sharing their experiences and vulnerabilities through reflection: "support and trust within the group ... the opportunity to discuss issues and be supported ... not being judged, you don't feel alone" [CCI]. A reference was made to both challenges and support, and there was evidence of "Increased level of challenge to one another - both in the group and outside of the group" [CCI].

\section{Translating into practice}

The translation of learning into workplace practice is depicted in Figure 3. The feedback supports that NUMs were transforming their development into actions: "I feel the benefit in my own learning in terms of taking away some of the ideas and implementing them here and seeing how they worked" [N1]. Implementing different approaches to problem solving as a result of sharing their own challenges and listening to the challenges brought to the group by their colleagues were discussed in the interviews:

I'm really starting to turn it around a bit and that's quite challenging for some people particularly my allied health colleagues as they are used to me taking on certain tasks that I'm now saying to them "are you alright to do that, what supports do you need to do that?" [N7]

The notion of changing the method of providing feedback was also discussed, as seen from this example:

I have actually given feedback in a more open forum, it was okay to do that, there was a message for the individual and 
for others about what is acceptable and not acceptable. I had

to really think about how to give that feedback. [CCI]

There is evidence of an increase in reflective practice: "I have learnt - rather than just crisis manage at the time; I tend to be more thinking about how I would work out an issue or work through an issue, rather than crisis manage it" [N1]. This was evident in combination with an increase in the criticality of the reflections:

I have got more awareness about critical reflection, and you know having the opportunity to have the ability to capture some of those issues, not necessarily issues, but capture them and maybe think about them more critically." [N4]

\section{How we see ourselves and how do we want to be seen?}

The fourth theme explores how the NUMs worked through the tensions that arose through engaging in this program, and also around those identified in the evaluation data (Figure 4). The facilitators were identified as playing a significant role in observing these tensions and pointing out contradictions to participants in a supportive way: "I valued the insight X (the facilitator) had to our roles and the offering of possible ways to address difficult situations" [CCI]. A difference between the internal voice and the external action of individuals was captured: "Knowing where your colleagues were coming from because externally they present well - internally they were having a lot of issues so that was really interesting" [N7]. When reflecting on an exercise undertaken regarding the identification of three things to be proud of about their leadership, the NUMs found this task to be difficult, as this manager outlined here: "took a lot of effort to think about those things that were working really well that we were really proud of " [N4]. This raised questions around how and when NUMs were getting feedback about their leadership.

The evaluation data revealed that there remains a lack of understanding in relation to critical feedback. One NUM reflects on the nature of the feedback they received:

I don't know whether if they have really given me feedback on my development as a leader but they do give me positive and not quite so positive feedback when I need it which is good. [N5]

The NUMs appear to grapple with the distinction between the roles of leadership versus management:

I think I always believe that the management side of the role are things that I needed to work on. I think my leadership skills I believed were pretty good and I still believe that ... [N4]
The importance of professionals engaging in critical reflection is highlighted:

I think when making a decision I guess you think more and reflect on whether or not it was informed, whether or not it was appropriate ... I think you do reflect more on the leadership and how you work as a leader. [N1]

Some NUMs discussed being experienced leaders; however, upon close examination, this was related to the length of time during which NUM was placed in a "leadership role" rather than on the depth of critical self-reflection, as noted in this quote that emerged when NUM was asked to reflect on his/her leadership before and after the program:

I think if I can steer away from that question, if I think what the group gave me - was an opportunity to reflect on my leadership journey and to see how far I have come and to be able to use some of my experience to help or assist/ encourage other people who have not had quite as much experience. [N2]

These comments articulate how the NUMs vacillated between various concepts and insights provoked by reflection, both individually and collectively. Organizational issues included the support for the NUM within the organization and the values managers and leaders have for the organization.

\section{Positive outcomes for me}

The final two themes relate to the outcomes for the individual NUM and for their outcomes as a group within the organization (Figure 5). Developing a sense of confidence in decisions and everyday challenges was described by many of the NUMs:

I am more confident to approach situations ... I think the course has helped me identify the right processes and the right skills and knowledge to actually approach situations. [N1]

The program provoked NUMs to learn about themselves and others: "I believe you can learn a lot about yourself through awareness of how you deal with situations compared to others" [N6]. This facilitated a connection between the group members: "I guess I work in an isolated sort of area in terms of the rest of the organization and it was good, I guess, to network with other managers" [N1], together with an affirmative and nurturing role: "validation for yourself - you're on track, doing the right thing" [N5]. The facilitation of skills was identified based on one skill set that the NUMs enjoyed learning, and they took back to the unit for implementation. A restorative function of the group was 
also highlighted: "I come feeling rubbished - I am leaving feeling better" [CCI].

\section{Positive outcomes for others}

Mentorship was a key factor in this theme, and it was both directly and indirectly described in the data. The NUMs perceived their role as a mentor to extend beyond their immediate relationships with each other, to the interdisciplinary teams they work with across the organization:

how I (am) perceived as a resource for others beyond the medical program is probably where the biggest change has been ... there are a couple of newer NUMs than me who I think (I) have been able to support in a much more active way as a result of the group participation than I would have otherwise simply because we are from different programs. [N3]

NUMs viewed themselves as change agents within the organization at both a micro- and macro-level, with networking in the program having an impact on the organization:

I do see that this has helped perhaps break down a little of that program alliance that you sometimes see because this sort of group means that you interact in a very intense sort of way sometimes with people you ordinarily would probably have very little to do with and broadening the NUM relationship perspective across the organization across the hospital ... you see different sorts of relationships and conversations occurring between NUMs from different programs. [N3]

The opportunity to develop leadership skills, knowledge, and attributes in a protected space and during a specific time was described as "a privilege" [N7]. These skills were shared with others: "it's about my ability to share my learning with the rest of the team and enabling them to take on some of those skills" [N4]. NUMs reflected on the idea that they felt the investment in their learning demonstrated that they were valued as health care professionals:

The group is about us, our learning, investment in our professional development, feeling valued ... recognition of the importance of the NUM's role and in us as individuals. [CCI]

This was also reflected upon in relation to the value the organization placed on the NUMs:

It is really respectful that the organization values the NUMs enough to say that we will put in a program of this type and give them an opportunity to attend some professional development for them so I think that's a real benefit. [N2]
Overwhelmingly, the responses in the evaluation indicated that the NUMs would like the program to continue. The CCI identified that the NUMs were interested in improving and informing future groups to enhance their learning and ongoing development.

\section{Discussion}

Nurse leaders are essential for providing safe person-centered care and establishing an effective workforce; despite this, investment in nursing leadership programs is lacking. ${ }^{715,19}$ This article details the qualitative results of an evaluation study of the NUM LDP within an Australian tertiary pediatric hospital. The program had a positive impact on the practice, and it provided an understanding of person-centered leadership for the participants. Similarly, a recent systematic review of nursing leadership found that all of the studies examining LDPs reported significantly positive outcomes on leadership. ${ }^{20}$

The findings from the NUM LDP corresponded with the five components of good leadership, as identified by Goleman: ${ }^{5}$ self-awareness; self-regulation; motivation; empathy; and the development of social skills - qualities which are integral to the NUM role. Participants indicated that the program was responsive to their current learning needs. This type of responsive learning process where individual needs are taken into account provides a level of congruence between learning outcomes and group processes. ${ }^{14} \mathrm{~A}$ focus on participants as developing individuals is consistent with a developmental learning framework and with transformative learning theory. ${ }^{21}$

In a recent review of health care professional education for the development of person-centered care, Lévesque et $\mathrm{a}^{22}$ cited critical reflection as a key component in patient-centered educational programs. Engaging in critical reflection within a "high challenge/high support" framework provides an opportunity to develop self-awareness. The learning environment the groups co-created in the NUM LDP promoted the development of self-regulation and empathy through the open sharing of reflections, providing and receiving feedback, and the enabling of skills to assist each other to solve problems. Leadership skills, knowledge, and insights were developed through sharing, together with challenging everyday practices, assumptions, and routine "ways of knowing." Duffield ${ }^{15}$ reported congruent findings in which NUMs learned from and through each other to achieve change and improved leadership performance.

The management versus leadership debate is well documented in the literature. ${ }^{22}$ Dignam et $\mathrm{al}^{23}$ highlighted the importance of facilitating clarity between leading teams through motivation, vision, and inspiration, versus managing 
operational tasks through control and planning, particularly in relation to the NUM role. The participants struggled with the distinction between leadership versus management; they vacillated between critically reviewing themselves as leaders whilst needing to maintain an external image of being effective leaders as an extension of being effective managers. Supporting NUMs to navigate the complexity associated with recognizing, developing, and implementing behaviors and attributes of leaders and managers is paramount.

\section{Recommendations}

Several key issues that need to be considered in planning ongoing leadership development for NUMs are highlighted. It is recommended that NUMs receive support to attend the program sessions, thus assisting them to engage in continual leadership development. Infrastructural support of leadership development efforts has been shown to assist in sustaining learning. ${ }^{8}$ Goleman ${ }^{5}$ discusses the importance of incorporating adequate time and individualized approaches into LDPs as essential in facilitating learning and behavioral change in the area of emotional intelligence. This approach in the NUM LDP provided the scaffolding upon which learning transpired. Evaluation of the curriculum should continue to occur during each session, and an annual overall program evaluation should be conducted, enabling facilitators and participants to shape the sessions as they progress to optimize positive outcomes. Demonstrating the quality of the programs, the evidence base used to inform curriculum development, together with the impact that such development has on service delivery, is vital to the provision of ongoing investment in programs such as these..$^{23,24}$

In planning LDPs, consideration should be given not only to factors such as the health care and organizational context, but also to other factors such as external drivers for program development, such as registration and tertiary or formal qualifications. ${ }^{24}$ It may be beneficial to incorporate reflection and learning into professional portfolios. In addition, the option for such programs to be recognized as a type of formal qualification by partnering with the educational sector should also be explored. The findings of this evaluation were provided to the organization, and endorsement to continue the program in 2012/2013 was received. There are currently 19 NUMs attending the program.

\section{Limitations of the study}

NUMs were encouraged to contribute their feedback, regardless of their attendance rate or their perception of whether they had outcomes to report. Additionally, the reporting of the findings had a high level of personal investment; therefore, this may have constrained what the respondents shared. Due to the fact that the interviews were conducted upon program completion, the findings regarding the program's evaluation reflected respondents' perceptions across a short term. Interview evaluation response rates were relatively low (41\%), although the feedback received through the CCI included almost all participants (94\%).

\section{Conclusion}

Effective person-centered leadership is essential for the provision of safe, high-quality person-centered care. Investing in the professional development of NUMs supports leadership development which, in turn, is associated with numerous workplace benefits, better patient outcomes, and improved health service delivery. By drawing on the literature that identifies the features of good leadership (such as emotional intelligence), we can see that the areas of self-awareness, self-regulation, motivation, and social awareness were developed through the use of experiential learning. This evaluation study showed the NUM LDP had a beneficial effect on the leadership practices of participants, and it also enhanced their understanding of person-centered leadership. Further research, particularly into the transferability of skills and the active participatory aspects of these types of evaluation studies, is required.

\section{Acknowledgments}

This study was internally funded. The authors thank the participating nurse unit managers and Annette Solman (Director of Nursing, Sydney Children's Hospitals Network) as the executive sponsor of the program. The authors would also like to thank Chris White for conducting the staff interviews (Nursing Research and Practice Development Unit, Sydney Children's Hospitals Network - Westmead). We also thank the Sydney Children's Hospitals Network - Westmead Nursing Executive.

\section{Disclosure}

The authors report no conflicts of interest in this work.

\section{References}

1. Wong CA, Cummings GG. The relationship between nursing leadership and patient outcomes: a systematic review. J Nurs Manag. 2007;15(5): 508-521.

2. Murphy L. Transformational leadership: a cascading chain reaction. J Nurs Manag. 2005;13(2):128-136.

3. Lucas V, Laschinger HK, Wong CA. The impact of emotional intelligent leadership on staff nurse empowerment: the moderating effect of span of control. J Nurs Manag. 2008;16(8):964-973. 
4. Walczak MB, Absolon PL. Essentials for effective communication in oncology nursing: assertiveness, conflict management, delegation, and motivation. J Nurses Staff Dev. 2001;17(3):159-162.

5. Goleman D. What makes a leader? Harv Bus Rev. 2004;82(1):82-91.

6. Kouzes JM, Posner BZ. The Leadership Challenge. San Francisco, CA: John Wiley \& Sons; 2007.

7. McGuire E, Kennerly SM. Nurse managers as transformational and transactional leaders. Nurs Econ. 2006;24(4):179-185.

8. Millward LJ, Bryan K. Clinical leadership in health care: a position statement. Int J Health Care Qual Assur Inc Leadersh Health Serv. 2005;18(2-3):xiii-xxv.

9. Edmonstone J, Western J. Leadership development in health care: what do we know? J Manag Med. 2002;16(1):34-47.

10. McCormack B, Dewing J, Breslin L, et al. Practice development: realising active learning for sustainable change. Contemp Nurse. 2009;32(1-2):92-104.

11. McCormack B, McCance T. Person-Centred Nursing: Theory and Practice. West Sussex, UK: Wiley-Blackwell; 2010.

12. Botwinick L, Bisognano M, Haraden C. Leadership Guide to Patient Safety. IHI Innovation Series white paper. Cambridge, UK: Institute for Healthcare Improvement; 2006.

13. Garling P. Final Report of the Special Commission of Inquiry: Acute Care Services in NSW Public Hospitals - Overview. Sydney, Australia: Special Commission of Inquiry; 2008.

14. Dierckx de Casterlé B, Willemse A, Verschueren M, Milisen K. Impact of clinical leadership development on the clinical leader, nursing team and care-giving process: a case study. J Nurs Manag. 2008;16(6):753-763.

15. Duffield C. A Master Class for nursing unit managers: an Australian example. J Nurs Manag. 2005;13(1):68-73.
16. Manley K, McCormack B, Wilson V. International Practice Development in Nursing and Healthcare. Oxford, UK: Blackwell Publishing, 2008.

17. McCormack B, Rycroft-Malone J, Decorby K, et al. A realist review of interventions and strategies to promote evidence-informed healthcare: a focus on change agency. Implement Sci. 2013;8(1):107.

18. Harvey G, Loftus-Hills A, Rycroft-Malone J, et al. Getting evidence into practice: the role and function of facilitation. J Adv Nurs. 2002;37(6): $577-588$.

19. O'Neil E, Morjikian RL, Cherner D, Hirschkorn C, West T. Developing nursing leaders: an overview of trends and programs. J Nurs Adm. 2008;38(4):178-183.

20. Cummings G, Lee H, Macgregor T, et al. Factors contributing to nursing leadership: a systematic review. J Health Serv Res Policy. 2008;13(4): 240-248.

21. Lévesque MC, Hovey RB, Bedos C. Advancing patient-centered care through transformative educational leadership: a critical review of health care professional preparation for patient-centred care. Journal of Healthcare Leadership. 2013;5:35-46.

22. Spurgeon P, Cragg R. Is it management or leadership? Clinician in Management. 2008;15:123-125.

23. Dignam D, Duffield C, Stasa H, Gray J, Jackson D, Daly J. Management and leadership in nursing: an Australian educational perspective. J Nurs Manag. 2012;20(1):65-71.

24. Vance C, Larson E. Leadership research in business and health care. J Nurs Scholarsh. 2002;34(2):165-171.
Journal of Healthcare Leadership

\section{Publish your work in this journal}

The Journal of Healthcare Leadership is an international, peer-reviewed, open access journal focusing on leadership for the health profession. The journal is committed to the rapid publication of research focusing on but not limited to: Healthcare policy and law; Theoretical and practical aspects healthcare delivery; Interactions between healthcare and society and evidence-based practices;

\section{Dovepress}

Interdisciplinary decision-making; Philosophical and ethical issues; Hazard management; Research and opinion for health leadership; Leadership assessment. The manuscript management system is completely online and includes a very quick and fair peer-review system. Visit http://www.dovepress.com/ testimonials.php to read real quotes from published authors. 